\title{
Convergence of Viscosity Iteration Process for a Finite Family of Generalized Asymptotically Quasi-Nonexpansive Mappings
}

\author{
Zhiming Cheng \\ College of Mathematics and Computer Science, Yangtze Normal University, Chongqing 408100, China \\ Correspondence should be addressed to Zhiming Cheng; fsxczm@yznu.cn
}

Received 22 August 2013; Revised 10 December 2013; Accepted 18 December 2013; Published 2 January 2014

Academic Editor: Fernando Simões

Copyright (C) 2014 Zhiming Cheng. This is an open access article distributed under the Creative Commons Attribution License, which permits unrestricted use, distribution, and reproduction in any medium, provided the original work is properly cited.

We introduce a general iteration method for a finite family of generalized asymptotically quasi-nonexpansive mappings. The results presented in the paper extend and improve some recent results in the works by Shahzad and Udomene (2006); L. Qihou (2001); Khan et al. (2008).

\section{Introduction and Preliminaries}

Let $C$ be a nonempty subset of a real Banach space $E$ and $T$ a self-mapping of $C$. The set of fixed points of $T$ is denoted by $F(T)$ and we assume that $F(T) \neq \emptyset$. The mapping $T$ is said to be

(i) contractive mapping if there exists a constant $\alpha$ in $(0,1)$ such that $\|f(x)-f(y)\| \leq \alpha\|x-y\|$, for all $x, y \in C$;

(ii) asymptotically nonexpansive mapping if there exists a sequence $\left\{u_{n}\right\}$ in $[0, \infty)$ with $\lim _{n \rightarrow \infty} u_{n}=0$ such that $\left\|T^{n} x-T^{n} y\right\| \leq\left(1+u_{n}\right)\|x-y\|$, for all $x, y \in C$ and $n=1,2,3, \ldots$;

(iii) asymptotically quasi-nonexpansive if there exists a sequence $\left\{u_{n}\right\}$ in $[0, \infty)$ with $\lim _{n \rightarrow \infty} u_{n}=0$ such that $\left\|T^{n} x-p\right\| \leq\left(1+u_{n}\right)\|x-p\|$, for all $x \in C, p \in F(T)$ and $n=1,2,3, \ldots$;

(iv) generalized asymptotically quasi-nonexpansive [1] if there exist two sequences $\left\{u_{n}\right\},\left\{h_{n}\right\}$ in $[0, \infty)$ with $\lim _{n \rightarrow \infty} u_{n}=0$ and $\lim _{n \rightarrow \infty} h_{n}=0$ such that

$\left\|T^{n} x-p\right\| \leq\left(1+u_{n}\right)\|x-p\|+h_{n}, \quad \forall x \in C, p \in F(T)$,

where $n=1,2,3, \ldots$;

(v) uniformly $L$-Lipschitzian if there exists a constant $L>$ 0 such that $\left\|T^{n} x-T^{n} y\right\| \leq L\|x-y\|$, for all $x, y \in C$ and $n=1,2,3, \ldots$; (vi) $(L-\gamma)$ uniform $L$-Lipschitz if there are constants $L>0$ and $\gamma>0$ such that $\left\|T^{n} x-T^{n} y\right\| \leq L\|x-y\|^{\gamma}$, for all $x, y \in C$ and $n=1,2,3, \ldots$;

(vii) semicompact if for a sequence $\left\{x_{n}\right\}$ in $C$ with $\lim _{n \rightarrow \infty}\left\|x_{n}-T x_{n}\right\|=0$, there exists a subsequence $\left\{x_{n_{i}}\right\}$ of $\left\{x_{n}\right\}$ such that $x_{n_{i}} \rightarrow p \in C$.

In (1), if $h_{n}=0$ for all $n \geq 1$, then $T$ becomes an asymptotically quasi-nonexpansive mapping; if $u_{n}=0$ and $h_{n}=0$ for all $n \geq 1$, then $T$ becomes a quasi-nonexpansive mapping. It is known that an asymptotically nonexpansive mapping is an asymptotically quasi-nonexpansive and a uniformly $L$ Lipschitzian mapping is $(L-1)$ uniform $L$-Lipschitz.

The mapping $T: C \rightarrow E$ is said to be demiclosed at 0 if for each sequence $\left\{x_{n}\right\} \subset C$ converging weakly to $x_{0}$ and $\left\{T x_{n}\right\}$ converging strongly to 0 , we have $T x_{0}=0$.

A Banach space $E$ is said to satisfy Opial's property if for each $x \in E$ and each sequence $\left\{x_{n}\right\}$ weakly convergent to $x$, the following condition holds for all $x \neq y$ :

$$
\liminf _{n \rightarrow \infty}\left\|x_{n}-x\right\|<\liminf _{n \rightarrow \infty}\left\|x_{n}-y\right\| .
$$

Let $C$ be a nonempty closed convex subset of a real Banach space $E$ and $\left\{T_{i}: i=1,2, \ldots k\right\}$ a finite family of asymptotically nonexpansive mappings of $C$ into itself. Suppose that 
$\alpha_{\text {in }} \in[0,1], n=1,2,3, \ldots$, and $i=1,2, \ldots k$. Then we consider the following mapping of $C$ into itself:

$$
\begin{aligned}
& U_{1 n}=\left(1-\alpha_{1 n}\right) I+\alpha_{1 n} T_{1}^{n} U_{0 n}, \\
& U_{2 n}=\left(1-\alpha_{2 n}\right) I+\alpha_{2 n} T_{2}^{n} U_{1 n}, \\
& \quad \vdots \\
& U_{(k-1) n}=\left(1-\alpha_{(k-1) n}\right) I+\alpha_{(k-1) n} T_{k-1}^{n} U_{(k-2) n}, \\
& W_{n}=U_{k n}=\left(1-\alpha_{k n}\right) I+\alpha_{k n} T_{k}^{n} U_{(k-1) n},
\end{aligned}
$$

where $U_{0 n}=I$ (identity mapping). Such a mapping $W_{n}$ is called the modified $W$-mapping generated by $T_{1}, T_{2}, \ldots, T_{k}$ and $\alpha_{1 n}, \alpha_{2 n}, \ldots, \alpha_{k n}$ (see $\left.[2,3]\right)$.

In the sequel, we assume that $F=\bigcap_{i=1}^{k} F\left(T_{i}\right)$.

In 2008, Khan et al. [4] introduced the following iteration process for a family of asymptotically quasi-nonexpansive mappings, for an arbitrary $x_{1} \in C$ :

$$
\begin{gathered}
y_{1 n}=\left(1-\alpha_{1 n}\right) x_{n}+\alpha_{1 n} T_{1}^{n} y_{0 n}, \\
y_{2 n}=\left(1-\alpha_{2 n}\right) x_{n}+\alpha_{2 n} T_{2}^{n} y_{1 n}, \\
\vdots \\
y_{(k-1) n}=\left(1-\alpha_{(k-1) n}\right) x_{n}+\alpha_{(k-1) n} T_{k-1}^{n} y_{(k-2) n}, \\
x_{n+1}=\left(1-\alpha_{k n}\right) x_{n}+\alpha_{k n} T_{k}^{n} y_{(k-1) n},
\end{gathered}
$$

where $y_{0 n}=x_{n}, \alpha_{i n} \in[0,1], i=1,2, \ldots, k, n=1,2, \ldots$ and proved that the iterative sequence $\left\{x_{n}\right\}$ defined by (4) converges strongly to a common fixed point of the family of mappings if and only if $\lim \inf _{n \rightarrow \infty} d\left(x_{n}, F\right)=0$, where $d(x, F)=$ inf $_{p \in F}\|x-p\|$. With the help of (3), we write (4) as

$$
x_{n+1}=W_{n} x_{n} .
$$

Recently, Chang et al. [5] introduced the following iteration process of asymptotically nonexpansive mappings in Banach space:

$$
\begin{gathered}
x_{n+1}=\lambda_{n} f\left(x_{n}\right)+\left(1-\lambda_{n}\right) T^{n} y_{n}, \\
y_{n}=\beta_{n} x_{n}+\left(1-\beta_{n}\right) T^{n} x_{n},
\end{gathered}
$$

where $\left\{\lambda_{n}\right\},\left\{\beta_{n}\right\} \subset[0,1]$ and $f$ is a fixed contractive mapping, and necessary and sufficient conditions are given for the iterative sequence $\left\{x_{n}\right\}$ to converge to the fixed points of $T$.

For a family of mappings, it is quite significant to devise a general iteration scheme which extends the iteration processes (4) and (6), simultaneously. Thereby, to achieve this goal, we introduce a new iteration process for a family of mappings as follows.

Let $C$ be a nonempty closed convex subset of a real Banach space $E,\left\{T_{i}: C \rightarrow C, i=1,2, \ldots, k\right\}$ a family of generalized asymptotically quasi-nonexpansive mappings, and $f: C \rightarrow$ $C$ a fixed contractive mapping with contractive coefficient $\alpha \in$ $(0,1)$. For a given $x_{1} \in C$, the iteration scheme is defined as follows:

$$
x_{n+1}=\lambda_{n} f\left(x_{n}\right)+\left(1-\lambda_{n}\right) W_{n} x_{n}
$$

where $\left\{\lambda_{n}\right\} \in[0,1]$ and $W_{n}$ is the modified $W$-mapping generated by $T_{1}, T_{2}, \ldots, T_{k}$, and $\alpha_{1 n}, \alpha_{2 n}, \ldots, \alpha_{k n}$ for all positive integers $n$.

The purpose of this paper is to study the convergence problem of the iterative sequences $\left\{x_{n}\right\}$ defined by (7). The obtained results extend the corresponding results in [4-8], and Lemma 11 partly improves the method of proof of Lemma 3.1 in [4].

In what follows, we need the following useful known lemmas.

Lemma 1 (see [9]). Let $\left\{a_{n}\right\},\left\{\delta_{n}\right\}$, and $\left\{\gamma_{n}\right\}$ be nonnegative real sequences satisfying the following condition:

$$
a_{n+1} \leq\left(1+\delta_{n}\right) a_{n}+\gamma_{n}
$$

where $\sum_{n=1}^{\infty} \delta_{n}<\infty$ and $\sum_{n=1}^{\infty} \gamma_{n}<\infty$; then $\lim _{n \rightarrow \infty} a_{n}$ exists.

Moreover, if in addition, $\lim \inf _{n \rightarrow \infty} a_{n}=0$, then $\lim _{n \rightarrow \infty} a_{n}=0$.

Lemma 2 (see [4]). Let E be a uniformly convex Banach space, $0<b \leq t_{n} \leq c<1$ for all $n \geq 1$, and let $\left\{x_{n}\right\}$ and $\left\{y_{n}\right\}$ be

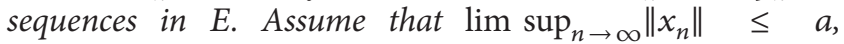
$\lim \sup _{n \rightarrow \infty}\left\|y_{n}\right\| \leq a$, and $\lim _{n \rightarrow \infty}\left\|t_{n} x_{n}+\left(1-t_{n}\right) y_{n}\right\|=a$ for some $a \geq 0$. Then $\lim _{n \rightarrow \infty}\left\|x_{n}-y_{n}\right\|=0$.

\section{Main Results}

Lemma 3. Let $C$ be a nonempty closed convex subset of a real Banach space $E$ and $T$ an asymptotically quasi-nonexpansive self-mapping of $C$ with $\left\{u_{n}\right\} \subset[0, \infty)$ for all $n \geq 1$. Suppose $F(T) \neq \phi$. Then $F(T)$ is a closed subset in $C$.

Proof. Let $\left\{z_{n}\right\}$ be an arbitrary sequence of $F(T)$ and $z_{n} \rightarrow z_{0}$ as $n \rightarrow \infty$. Since $C$ is closed, we have $z_{0} \in C$. For any $\epsilon>0$, there exists a natural number $N$ such that

$$
\left\|z_{n}-z_{0}\right\|<\frac{\epsilon}{2+u_{1}}, \quad \forall n \geq N .
$$

Thus, we get

$$
\begin{aligned}
\left\|T z_{0}-z_{0}\right\| & \leq\left\|T z_{0}-z_{N}\right\|+\left\|z_{N}-z_{0}\right\| \\
& \leq\left(1+u_{1}\right)\left\|z_{N}-z_{0}\right\|+\left\|z_{N}-z_{0}\right\| \\
& =\left(2+u_{1}\right)\left\|z_{N}-z_{0}\right\|<\epsilon .
\end{aligned}
$$

Since $\epsilon$ is arbitrary, it follows that $\left\|T z_{0}-z_{0}\right\|=0$; that is, $T z_{0}=$ $z_{0}$. Hence $z_{0} \in F(T)$ and $F(T)$ is closed. This completes the proof.

Lemma 4. Let $C$ be a nonempty closed convex subset of a real Banach space $E$. Let $\left\{T_{i}: i=1,2, \ldots, k\right\}$ be $k$ generalized asymptotically quasi-nonexpansive self-mappings of $C$ with $\left\{u_{i n}\right\},\left\{h_{i n}\right\} \subset[0, \infty)$ such that $\sum_{n=1}^{\infty} u_{i n}<\infty$ and $\sum_{n=1}^{\infty} h_{i n}<$ $\infty$ for all $i \in\{1,2,3, \ldots, k\}$. Suppose $F \neq \emptyset$ and $\left\{\alpha_{i n}\right\}_{n \geq 1} \subset[0,1]$ for all $i \in\{1,2,3, \ldots, k\}$. Let $W_{n}$ be the modified $W$-mapping generated by $T_{1}, T_{2}, \ldots, T_{k}$ and $\alpha_{1 n}, \alpha_{2 n}, \ldots, \alpha_{k n}$. Let the sequence $\left\{x_{n}\right\}$ be defined by (7) and assuming $\sum_{n=1}^{\infty} \lambda_{n}<\infty$, then 
(1) there exist two sequences $\left\{v_{n}\right\}$ and $\left\{\xi_{n}\right\}$ in $[0, \infty)$ with $\sum_{n=1}^{\infty} v_{n}<\infty, \sum_{n=1}^{\infty} \xi_{n}<\infty$ such that

$\left\|x_{n+1}-p\right\| \leq\left(1+v_{n}\right)^{k}\left\|x_{n}-p\right\|+\xi_{n}, \quad \forall p \in F, n \geq 1 ;$

(2) there exists a constant $M_{1}>0$, such that

$$
\begin{gathered}
\left\|x_{n+m}-p\right\| \leq M_{1}\left\|x_{n}-p\right\|+M_{1} \sum_{i=n}^{\infty} \xi_{i}, \\
\forall p \in F, n, m=1,2,3, \ldots,
\end{gathered}
$$

where $\left\{\xi_{n}\right\} \in[0, \infty)$ and $\Sigma_{n=1}^{\infty} \xi_{n}<\infty$.

Proof. (1) Let $v_{n}=\max _{1 \leq i \leq k} u_{i n}$, for all $n$. Since $\sum_{n=1}^{\infty} u_{i n}<\infty$ for each $i$, we can get $\sum_{n=1}^{\infty} v_{n}<\infty$. For all $p \in F$, it follows from (3) that

$$
\begin{aligned}
\left\|U_{1 n} x_{n}-p\right\| \leq & \left(1-\alpha_{1 n}\right)\left\|x_{n}-p\right\|+\alpha_{1 n}\left\|T_{1}^{n} x_{n}-p\right\| \\
\leq & \left(1-\alpha_{1 n}\right)\left\|x_{n}-p\right\| \\
& +\alpha_{1 n}\left[\left(1+u_{1 n}\right)\left\|x_{n}-p\right\|+h_{1 n}\right] \\
\leq & \left(1+u_{1 n}\right)\left\|x_{n}-p\right\|+h_{1 n} \\
\leq & \left(1+v_{n}\right)\left\|x_{n}-p\right\|+h_{1 n} .
\end{aligned}
$$

Assume that $\left\|U_{j n} x_{n}-p\right\| \leq\left(1+v_{n}\right)^{j}\left\|x_{n}-p\right\|+\left(1+v_{n}\right)^{j-1} \sum_{i=1}^{j} h_{i n}$ for some $1 \leq j \leq k-1$. Then

$$
\begin{aligned}
&\left\|U_{(j+1) n} x_{n}-p\right\| \\
& \leq\left(1-\alpha_{(j+1) n}\right)\left\|x_{n}-p\right\| \\
&+\alpha_{(j+1) n}\left\|T_{j+1}^{n} U_{j n} x_{n}-p\right\| \\
& \leq\left(1-\alpha_{(j+1) n}\right)\left\|x_{n}-p\right\| \\
&+\alpha_{(j+1) n}\left(\left(1+u_{(j+1) n}\right)\left\|U_{j n} x_{n}-p\right\|+h_{(j+1) n}\right) \\
& \leq\left(1-\alpha_{(j+1) n}\right)\left\|x_{n}-p\right\|+\alpha_{(j+1) n} h_{(j+1) n} \\
&+\alpha_{(j+1) n}\left(1+u_{(j+1) n}\right) \\
& \times\left(\left(1+v_{n}\right)^{j}\left\|x_{n}-p\right\|+\left(1+v_{n}\right)^{j-1} \sum_{i=1}^{j} h_{i n}\right) \\
& \leq\left(\left(1-\alpha_{(j+1) n}\right)+\alpha_{(j+1) n}\left(1+v_{n}\right)^{j+1}\right)\left\|x_{n}-p\right\| \\
&+\left(1+v_{n}\right)^{j} \sum_{i=1}^{j} h_{i n}+h_{(j+1) n} \\
& \leq\left(\left(1-\alpha_{(j+1) n}\right)\left(1+v_{n}\right)^{j+1}+\alpha_{(j+1) n}\left(1+v_{n}\right)^{j+1}\right)
\end{aligned}
$$

$$
\begin{gathered}
\times\left\|x_{n}-p\right\|+\left(1+v_{n}\right)^{j} \sum_{i=1}^{j+1} h_{i n} \\
\leq\left(1+v_{n}\right)^{j+1}\left\|x_{n}-p\right\|+\left(1+v_{n}\right)^{j} \sum_{i=1}^{j+1} h_{i n} .
\end{gathered}
$$

Thus, by induction, we have

$$
\left\|U_{j n} x_{n}-p\right\| \leq\left(1+v_{n}\right)^{j}\left\|x_{n}-p\right\|+\left(1+v_{n}\right)^{j-1} \sum_{i=1}^{j} h_{i n},
$$

for all $j=1,2, \ldots, k$. Hence,

$$
\begin{aligned}
\left\|W_{n} x_{n}-p\right\|= & \left\|U_{k n} x_{n}-p\right\| \leq\left(1+v_{n}\right)^{k}\left\|x_{n}-p\right\| \\
& +\left(1+v_{n}\right)^{k-1} \sum_{i=1}^{k} h_{i n} .
\end{aligned}
$$

By (7) and (16), we obtain

$$
\begin{aligned}
\left\|x_{n+1}-p\right\| \leq & \lambda_{n}\left\|f\left(x_{n}\right)-p\right\|+\left(1-\lambda_{n}\right)\left\|W_{n} x_{n}-p\right\| \\
\leq & \lambda_{n}\left\|f\left(x_{n}\right)-f(p)\right\|+\lambda_{n}\|f(p)-p\| \\
& +\left(1-\lambda_{n}\right)\left\|W_{n} x_{n}-p\right\| \\
\leq & \lambda_{n} \alpha\left\|x_{n}-p\right\|+\lambda_{n}\|f(p)-p\|+\left(1-\lambda_{n}\right) \\
& \times\left[\left(1+v_{n}\right)^{k}\left\|x_{n}-p\right\|+\left(1+v_{n}\right)^{k-1} \sum_{i=1}^{k} h_{i n}\right] \\
\leq & \left(1+v_{n}\right)^{k}\left\|x_{n}-p\right\| \\
& +\left(1-\lambda_{n}\right)\left(1+v_{n}\right)^{k-1} \sum_{i=1}^{k} h_{i n} \\
& +\lambda_{n}\|f(p)-p\| .
\end{aligned}
$$

Since $\sum_{n=1}^{\infty} v_{n}<\infty,\left\{v_{n}\right\}_{n=1}^{\infty}$ is bounded. Setting $M=$ $\max \left\{\sup _{n}\left(1+v_{n}\right)^{k-1},\|f(p)-p\|\right\}$, we get that

$$
\left\|x_{n+1}-p\right\| \leq\left(1+v_{n}\right)^{k}\left\|x_{n}-p\right\|+\xi_{n}, \quad \forall p \in F, n \geq 1,
$$

where $\xi_{n}=M\left(\sum_{i=1}^{k} h_{i n}+\lambda_{n}\right)$ and $\sum_{n=1}^{\infty} \xi_{n}<\infty$. This completes the proof of (1).

(2) If $t \geq 0$, then $1+t \leq e^{t}$ and consequently, $(1+t)^{k} \leq e^{k t}$, $k=1,2, \ldots$. Thus, from part (1), we get

$$
\begin{aligned}
\left\|x_{n+m}-p\right\| \leq & \left(1+v_{n+m-1}\right)^{k}\left\|x_{n+m-1}-p\right\|+\xi_{n+m-1} \\
\leq & \exp \left\{k v_{n+m-1}\right\}\left\|x_{n+m-1}-p\right\|+\xi_{n+m-1} \\
\leq & \exp \left\{k v_{n+m-1}\right\} \\
& \times\left(\exp \left\{k v_{n+m-2}\right\}\left\|x_{n+m-2}-p\right\|+\xi_{n+m-2}\right) \\
& +\xi_{n+m-1}
\end{aligned}
$$




$$
\begin{aligned}
& \leq \exp \left\{k\left(v_{n+m-1}+v_{n+m-2}\right)\right\}\left\|x_{n+m-2}-p\right\| \\
& \quad+\exp \left\{k v_{n+m-1}\right\}\left(\xi_{n+m-2}+\xi_{n+m-1}\right) \\
& \vdots \\
& \leq \exp \left\{k \sum_{i=n}^{n+m-1} v_{i}\right\}\left\|x_{n}-p\right\| \\
& \quad+\exp \left\{k \sum_{i=n+1}^{n+m-1} v_{i}\right\} \sum_{i=n}^{n+m-1} \xi_{i} \\
& \leq M_{1}\left\|x_{n}-p\right\|+M_{1} \sum_{i=n}^{\infty} \xi_{i}
\end{aligned}
$$

for any positive integers $m, n$, where $M_{1}=\exp \left\{k \sum_{i=1}^{\infty} v_{i}\right\}$, $\sum_{i=1}^{\infty} \xi_{i}<\infty$. This completes the proof of (2).

Remark 5. Lemma 4 generalizes Lemma 2.1 in [4].

Theorem 6. Let $C$ be a nonempty closed convex subset of a real Banach space E. Let $\left\{T_{i}: i=1,2, \ldots, k\right\}$ be $k$ generalized asymptotically quasi-nonexpansive self-mappings of $C$ with $\left\{u_{i n}\right\},\left\{h_{i n}\right\} \subset[0, \infty)$ such that $\sum_{n=1}^{\infty} u_{i n}<\infty$ and $\sum_{n=1}^{\infty} h_{i n}<$ $\infty$ for all $i \in\{1,2,3, \ldots, k\}$. Let $\left\{\alpha_{i n}\right\}_{n \geq 1} \subset[0,1]$ for all $i \in$ $\{1,2,3, \ldots, k\}$ and let $W_{n}$ be a modified $W$-mapping generated by $T_{1}, T_{2}, \ldots, T_{k}$ and $\alpha_{1 n}, \alpha_{2 n}, \ldots, \alpha_{k n}$. Suppose that $F \neq \emptyset$ is closed and $\sum_{n=1}^{\infty} \lambda_{n}<\infty$. Starting from arbitrary $x_{1} \in C$, define the sequence $\left\{x_{n}\right\}$ by the recursion (7); then the sequence $\left\{x_{n}\right\}$ converges strongly to $p \in F$ if and only if $\lim \inf _{n \rightarrow \infty} d\left(x_{n}, F\right)=0$.

Proof. We will only prove the sufficiency; the necessity is obvious. From Lemma 4(1), we have

$$
\left\|x_{n+1}-p\right\| \leq\left(1+v_{n}\right)^{k}\left\|x_{n}-p\right\|+\xi_{n}
$$

for all $p \in F$ and all $n$. Therefore,

$$
\begin{aligned}
d\left(x_{n+1}, F\right) \leq & \left(1+v_{n}\right)^{k} d\left(x_{n}, F\right)+\xi_{n} \\
= & \left(1+\sum_{r=1}^{k} \frac{k(k-1) \cdots(k-r+1)}{r !} v_{n}^{r}\right) \\
& \times d\left(x_{n}, F\right)+\xi_{n} .
\end{aligned}
$$

As $\sum_{n=1}^{\infty} \nu_{n}<\infty$, so $\sum_{r=1}^{k}(k(k-1) \cdots(k-r+1) / r$ ! $) v_{n}^{r}<\infty$. By Lemma 1 and $\lim _{n \rightarrow \infty} d\left(x_{n}, F\right)=0$, we get that $\lim _{n \rightarrow \infty} d\left(x_{n}, F\right)=0$. Next, we prove that $\left\{x_{n}\right\}$ is a Cauchy sequence. From Lemma 4(2), we have

$$
\left\|x_{n+m}-p\right\| \leq M_{1}\left\|x_{n}-p\right\|+M_{1} \sum_{i=n}^{\infty} \xi_{i}
$$

Hence, for all integers $m \geq 1$ and all $p \in F$,

$$
\begin{aligned}
\left\|x_{n+m}-x_{n}\right\| & \leq\left\|x_{n+m}-p\right\|+\left\|x_{n}-p\right\| \\
& \leq\left(M_{1}+1\right)\left\|x_{n}-p\right\|+M_{1} \sum_{j=n}^{\infty} \xi_{j} .
\end{aligned}
$$

Taking infimum over $p \in F$ in (23) gives

$$
\left\|x_{n+m}-x_{n}\right\| \leq\left(M_{1}+1\right) d\left(x_{n}, F\right)+M_{1} \sum_{j=n}^{\infty} \xi_{j} .
$$

Now, since $\lim _{n \rightarrow \infty} d\left(x_{n}, F\right)=0$ and $\sum_{j=1}^{\infty} \xi_{j}<\infty$, given $\epsilon>$ 0 , there exists an integer $N_{1}>0$ such that for all $n \geq N_{1}$, $d\left(x_{n}, F\right)<\epsilon /\left(2\left(M_{1}+2\right)\right)$ and $\sum_{j=n}^{\infty} \xi_{n}<\epsilon /\left(2\left(M_{1}+1\right)\right)$. So for all integers $n \geq N_{1}, m \geq 1$, we obtain from (24) that

$$
\left\|x_{n+m}-x_{n}\right\|<\epsilon, \quad \forall n \geq N_{1}, \quad m \geq 1 .
$$

Hence, $\left\{x_{n}\right\}$ is a Cauchy sequence in $E$. Since $E$ is complete, there exists $q \in E$ such that $\lim _{n \rightarrow \infty} x_{n}=q$. We now show that $q \in F$. Since $d\left(x_{n}, F\right) \rightarrow 0$ and $x_{n} \rightarrow q$ as $n \rightarrow \infty$, for each $\bar{\epsilon}>0$, there exists an integer $N_{2}>0$ such that, $d\left(x_{n}, F\right)=$ inf $_{p \in F}\left\|x_{n}-p\right\|<\bar{\epsilon} / 3$ and $\left\|x_{n}-q\right\|<\bar{\epsilon} / 2$ for all $n \geq N_{2}$. In particular, we have $d\left(x_{N_{2}}, F\right)=\inf _{p \in F}\left\|x_{N_{2}}-p\right\|<\bar{\epsilon} / 3$; that is, there exists a $\bar{p} \in F$ such that $\left\|x_{N_{2}}-\bar{p}\right\|<\bar{\epsilon} / 2$; hence

$$
\|q-\bar{p}\| \leq\left\|x_{N_{2}}-q\right\|+\left\|x_{N_{2}}-\bar{p}\right\|<\bar{\epsilon} .
$$

Since $F$ is a closed subset of $E$, we obtain $q \in F$. This completes the proof.

Remark 7. Theorem 6 generalizes and extends Theorem 2.2 of Khan et al. [4], Theorem 3.1 of Ghosh and Debnath [8], Theorem 3.2 of Shahzad and Udomene [6], and Theorem 1 of Qihou [7] together with its Corollaries 1 and 2.

Asymptotically nonexpansive mappings and asymptotically quasi-nonexpansive mappings are all generalized asymptotically quasi-nonexpansive, by Theorem 6 and Lemma 3, so we have

Corollary 8. Let $C$ be a nonempty closed convex subset of a real Banach space E. Let $\left\{T_{i}: i=1,2, \ldots, k\right\}$ be $k$ asymptotically quasi-nonexpansive self-mappings of $C$ with $\left\{u_{i n}\right\} \subset$ $[0, \infty)$ such that $\sum_{n=1}^{\infty} u_{i n}<\infty$ for all $i \in\{1,2,3, \ldots, k\}$. Let $\left\{\alpha_{i n}\right\}_{n \geq 1} \subset[0,1]$ for all $i \in\{1,2,3, \ldots, k\}$ and let $W_{n}$ be a modified $W$-mapping generated by $T_{1}, T_{2}, \ldots, T_{k}$ and $\alpha_{1 n}, \alpha_{2 n}, \ldots, \alpha_{k n}$. Suppose $F \neq \emptyset$ and $\sum_{n=1}^{\infty} \lambda_{n}<\infty$. Starting from arbitrary $x_{1} \in C$, define the sequence $\left\{x_{n}\right\}$ by the recursion (7). Then the sequence $\left\{x_{n}\right\}$ converges strongly to $p \in F$ if and only if $\lim \inf _{n \rightarrow \infty} d\left(x_{n}, F\right)=0$.

Corollary 9. Let $C$ be a nonempty closed convex subset of a real Banach space E. Let $\left\{T_{i}: i=1,2, \ldots, k\right\}$ be $k$ asymptotically nonexpansive self-mappings of $C$ with $\left\{u_{i n}\right\} \subset[0, \infty)$ such that $\sum_{n=1}^{\infty} u_{i n}<\infty$ for all $i \in\{1,2,3, \ldots, k\}$. Let $\left\{\alpha_{i n}\right\}_{n \geq 1} \subset$ $[0,1]$ for all $i \in\{1,2,3, \ldots, k\}$ and let $W_{n}$ be a modified $W$-mapping generated by $T_{1}, T_{2}, \ldots, T_{k}$ and $\alpha_{1 n}, \alpha_{2 n}, \ldots, \alpha_{k n}$. 
Suppose $F \neq \emptyset$ and $\sum_{n=1}^{\infty} \lambda_{n}<\infty$. Starting from arbitrary $x_{1} \in$ $C$, define the sequence $\left\{x_{n}\right\}$ by the recursion (7). Then the sequence $\left\{x_{n}\right\}$ converges strongly to $p \in F$ if and only if $\lim \inf _{n \rightarrow \infty} d\left(x_{n}, F\right)=0$.

Corollary 10. Let $C$ be a nonempty closed convex subset of a real Banach space E. Let $\left\{T_{i}: i=1,2, \ldots, k\right\}$ be $k$ generalized asymptotically quasi-nonexpansive self-mappings of $C$ with $\left\{u_{i n}\right\},\left\{h_{i n}\right\} \subset[0, \infty)$ such that $\sum_{n=1}^{\infty} u_{i n}<\infty$ and $\sum_{n=1}^{\infty} h_{i n}<$ $\infty$ for all $i \in\{1,2,3, \ldots, k\}$. Let $\left\{\alpha_{i n}\right\}_{n \geq 1} \subset[0,1]$ for all $i \in$ $\{1,2,3, \ldots, k\}$ and let $W_{n}$ be a modified $W$-mapping generated by $T_{1}, T_{2}, \ldots, T_{k}$ and $\alpha_{1 n}, \alpha_{2 n}, \ldots, \alpha_{k n}$. Suppose that $F \neq \emptyset$ is closed and $\sum_{n=1}^{\infty} \lambda_{n}<\infty$. Starting from arbitrary $x_{1} \in C$, define the sequence $\left\{x_{n}\right\}$ by the recursion (7). Then the sequence $\left\{x_{n}\right\}$ converges strongly to $p \in F$ if and only if there exists a subsequence $\left\{x_{n_{j}}\right\}$ of $\left\{x_{n}\right\}$ which converges to $p$.

\section{Results in Uniformly Convex Banach Spaces}

Lemma 11. Let $C$ be a nonempty closed convex subset of a uniformly convex Banach space E. Let $\left\{T_{i}: i=1,2, \ldots, k\right\}$ be $k(L-\gamma)$ uniform Lipschitz and generalized asymptotically quasi-nonexpansive self-mappings of $C$ with $\left\{u_{i n}\right\},\left\{h_{i n}\right\} \quad C$ $[0, \infty)$ such that $\sum_{n=1}^{\infty} u_{i n}<\infty$ and $\sum_{n=1}^{\infty} h_{i n}<\infty$ for all $i \epsilon$ $\{1,2,3, \ldots, k\}$. Let $\alpha_{i n} \in[\delta, 1-\delta]$ for some $\delta \in(0,1 / 2)$ and let $W_{n}$ be a modified $W$-mapping generated by $T_{1}, T_{2}, \ldots, T_{k}$ and $\alpha_{1 n}, \alpha_{2 n}, \ldots, \alpha_{k n}$. Suppose $F=\bigcap_{i=1}^{k} F\left(T_{i}\right) \neq \emptyset$ and $\sum_{n=1}^{\infty} \lambda_{n}<$ $\infty$. Starting from arbitrary $x_{1} \in C$, define the sequence $\left\{x_{n}\right\}$ by the recursion (7). Then $\lim _{n \rightarrow \infty}\left\|x_{n}-T_{j} x_{n}\right\|=0$ for each $j \in$ $\{1,2,3, \ldots k\}$.

Proof. Let $p \in F$ and $v_{n}=\max _{1 \leq i \leq k} u_{i n}$, for all $n$. By Lemma 1 and Lemma 4(1), it follows that $\lim _{n \rightarrow \infty}\left\|x_{n}-p\right\|$ exists for all $p \in F$. Assume that

$$
\lim _{n \rightarrow \infty}\left\|x_{n}-p\right\|=c
$$

From (2) and (27) we obtain that

$$
\limsup _{n \rightarrow \infty}\left\|U_{j n} x_{n}-p\right\| \leq c, \quad \forall 1 \leq j \leq k .
$$

From (7), we have

$$
\begin{aligned}
\left\|x_{n+1}-p\right\|= & \left\|\lambda_{n} f\left(x_{n}\right)+\left(1-\lambda_{n}\right) W_{n} x_{n}-p\right\| \\
\leq & \lambda_{n} \alpha\left\|x_{n}-p\right\|+\lambda_{n}\|f(p)-p\| \\
& +\left(1-\lambda_{n}\right)\left\|U_{k n} x_{n}-p\right\| ;
\end{aligned}
$$

therefore,

$$
\liminf _{n \rightarrow \infty}\left\|U_{k n} x_{n}-p\right\| \geq c .
$$

From (28) and (30) we can obtain that

$$
\lim _{n \rightarrow \infty}\left\|U_{k n} x_{n}-p\right\|=c
$$

Suppose that $\lim _{n \rightarrow \infty}\left\|U_{(j+1) n} x_{n}-p\right\|=c$ for some $1 \leq j \leq$ $k-1$. Since

$$
\begin{aligned}
\left\|U_{(j+1) n} x_{n}-p\right\| \leq & \left(1-\alpha_{(j+1) n}\right)\left\|x_{n}-p\right\| \\
& +\alpha_{(j+1) n}\left\|T_{j+1}^{n} U_{j n} x_{n}-p\right\| \\
\leq & \left(1-\alpha_{(j+1) n}\right)\left\|x_{n}-p\right\|+\alpha_{(j+1) n} \\
& \times\left[\left(1+u_{(j+1) n}\right)\left\|U_{j n} x_{n}-p\right\|+h_{(j+1) n}\right],
\end{aligned}
$$

so we obtain that

$$
\liminf _{n \rightarrow \infty}\left\|U_{j n} x_{n}-p\right\| \geq c .
$$

From (28) and (33), we have that

$$
\lim _{n \rightarrow \infty}\left\|U_{j n} x_{n}-p\right\|=c .
$$

Thus, by induction, we have

$$
\lim _{n \rightarrow \infty}\left\|U_{j n} x_{n}-p\right\|=c,
$$

for each $j=1,2,3, \ldots, k$. That is,

$$
\lim _{n \rightarrow \infty}\left\|\left(1-\alpha_{j n}\right)\left(x_{n}-p\right)+\alpha_{j n}\left(T_{j}^{n} U_{(j-1) n} x_{n}-p\right)\right\|=c,
$$

for each $j=1,2,3, \ldots, k$. From (28), we obtain

$$
\limsup _{n \rightarrow \infty}\left\|T_{j}^{n} U_{(j-1) n} x_{n}-p\right\| \leq c,
$$

for each $j=1,2,3, \ldots, k$. By Lemma 2 , we get

$$
\lim _{n \rightarrow \infty}\left\|T_{j}^{n} U_{(j-1) n} x_{n}-x_{n}\right\|=0, \quad \forall 1 \leq j \leq k .
$$

If $j=1$, from (38), we have

$$
\lim _{n \rightarrow \infty}\left\|T_{1}^{n} x_{n}-x_{n}\right\|=0 .
$$

If $j=2,3, \ldots, k$, then we have

$$
\begin{aligned}
\left\|T_{j}^{n} x_{n}-x_{n}\right\| \leq & \left\|T_{j}^{n} x_{n}-T_{j}^{n} U_{(j-1) n} x_{n}\right\|+\left\|T_{j}^{n} U_{(j-1) n} x_{n}-x_{n}\right\| \\
\leq & L\left\|x_{n}-U_{(j-1) n} x_{n}\right\|^{\gamma} \\
& +\left\|T_{j}^{n} U_{(j-1) n} x_{n}-x_{n}\right\| \\
= & L\left(\alpha_{(j-1) n}\left\|x_{n}-T_{j-1}^{n} U_{(j-2) n} x_{n}\right\|\right)^{\gamma} \\
& +\left\|T_{j}^{n} U_{(j-1) n} x_{n}-x_{n}\right\| .
\end{aligned}
$$

Hence,

$$
\lim _{n \rightarrow \infty}\left\|T_{j}^{n} x_{n}-x_{n}\right\|=0, \quad \forall 1 \leq j \leq k .
$$

Note that

$$
\begin{aligned}
\left\|x_{n+1}-x_{n}\right\| & =\left\|\lambda_{n} f\left(x_{n}\right)+\left(1-\lambda_{n}\right) W_{n} x_{n}-x_{n}\right\| \\
& \leq \lambda_{n}\left(\alpha\left\|x_{n}-p\right\|+\|f(p)-p\|+\left\|x_{n}-p\right\|\right)
\end{aligned}
$$




$$
\begin{aligned}
& +\left(1-\lambda_{n}\right)\left\|W_{n} x_{n}-x_{n}\right\| \\
= & \lambda_{n}\left(\alpha\left\|x_{n}-p\right\|+\|f(p)-p\|+\left\|x_{n}-p\right\|\right) \\
& +\left(1-\lambda_{n}\right) \alpha_{k n}\left\|T_{k}^{n} U_{(k-1) n} x_{n}-x_{n}\right\| ;
\end{aligned}
$$

therefore, we have

$$
\lim _{n \rightarrow \infty}\left\|x_{n+1}-x_{n}\right\|=0 .
$$

Now, we observe that

$$
\begin{aligned}
\left\|x_{n}-T_{j} x_{n}\right\| \leq & \left\|x_{n}-x_{n+1}\right\|+\left\|x_{n+1}-T_{j}^{n+1} x_{n+1}\right\| \\
& +\left\|T_{j}^{n+1} x_{n+1}-T_{j}^{n+1} x_{n}\right\|+\left\|T_{j}^{n+1} x_{n}-T_{j} x_{n}\right\| \\
\leq & \left\|x_{n}-x_{n+1}\right\|+\left\|x_{n+1}-T_{j}^{n+1} x_{n+1}\right\| \\
& +L\left\|x_{n+1}-x_{n}\right\|^{\gamma}+L\left\|T_{j}^{n} x_{n}-x_{n}\right\|^{\gamma} .
\end{aligned}
$$

By (41) and (43), we have

$$
\lim _{n \rightarrow \infty}\left\|x_{n}-T_{j} x_{n}\right\|=0
$$

for $j=1,2,3, \ldots, k$. This completes the proof.

Theorem 12. Let $C$ be a nonempty closed convex subset of a uniformly convex Banach space $E$. Let $\left\{T_{i}: i=1,2, \ldots, k\right\}$ be $k(L-\gamma)$ uniform Lipschitz and generalized asymptotically quasi-nonexpansive self-mappings of $C$ with $\left\{u_{i n}\right\},\left\{h_{i n}\right\} \quad C$ $[0, \infty)$ such that $\sum_{n=1}^{\infty} u_{i n}<\infty$ and $\sum_{n=1}^{\infty} h_{i n}<\infty$ for all $i \epsilon$ $\{1,2,3, \ldots, k\}$. Let $\alpha_{i n} \in[\delta, 1-\delta]$ for some $\delta \in(0,1 / 2)$ and let $W_{n}$ be a modified $W$-mapping generated by $T_{1}, T_{2}, \ldots, T_{k}$ and $\alpha_{1 n}, \alpha_{2 n}, \ldots, \alpha_{k n}$. Suppose $F=\bigcap_{i=1}^{k} F\left(T_{i}\right) \neq \emptyset, \sum_{n=1}^{\infty} \lambda_{n}<\infty$ and there exists one member in $\left\{T_{i}^{m}: i=1,2, \ldots, k\right\}$ which is semicompact for some positive integer $m$. Starting from arbitrary $x_{1} \in C$, define the sequence $\left\{x_{n}\right\}$ by the recursion (7). Then $\left\{x_{n}\right\}$ converges strongly to some common fixed point of the family $\left\{T_{i}: i=1,2, \ldots, k\right\}$.

Proof. By Lemma 11, we have

$$
\lim _{n \rightarrow \infty}\left\|x_{n}-T_{j} x_{n}\right\|=0
$$

for each $j=1,2,3, \ldots k$. Without loss of generality, we may assume that $T_{1}^{m}$ is semicompact for some $m \geq 1$; then we have

$$
\begin{aligned}
\left\|T_{1}^{m} x_{n}-x_{n}\right\| \leq & \left\|T_{1}^{m} x_{n}-T_{1}^{m-1} x_{n}\right\|+\left\|T_{1}^{m-1} x_{n}-T_{1}^{m-2} x_{n}\right\| \\
& +\cdots+\left\|T_{1} x_{n}-x_{n}\right\| \\
\leq & \left\|T_{1} x_{n}-x_{n}\right\|+(m-1) L\left\|T_{1} x_{n}-x_{n}\right\|^{\gamma} \longrightarrow 0 .
\end{aligned}
$$

Since $T_{1}^{m}$ is semicompact, then there exists a subsequence $\left\{x_{n_{j}}\right\}$ of $\left\{x_{n}\right\}$ such that $x_{n_{j}} \rightarrow q \in C$. Hence, we have

$$
\left\|q-T_{i} q\right\|=\lim _{j \rightarrow \infty}\left\|x_{n_{j}}-T_{j} x_{n_{j}}\right\|=0
$$

for each $i=1,2,3, \ldots, k$. This implies that $q \in F$. By Corollary 10, $\left\{x_{n}\right\}$ converges strongly to some common fixed point of the family $\left\{T_{i}: i=1,2, \ldots, k\right\}$.

Theorem 13. Let $C$ be a nonempty closed convex subset of a uniformly convex Banach space E. Let $\left\{T_{i}: i=1,2, \ldots, k\right\}$ be $k(L-\gamma)$ uniform Lipschitz and generalized asymptotically quasi-nonexpansive self-mappings of $C$ with $\left\{u_{i n}\right\},\left\{h_{i n}\right\} \quad C$ $[0, \infty)$ such that $\sum_{n=1}^{\infty} u_{i n}<\infty$ and $\sum_{n=1}^{\infty} h_{i n}<\infty$ for all $i \epsilon$ $\{1,2,3, \ldots, k\}$. Let $\alpha_{i n} \in[\delta, 1-\delta]$ for some $\delta \in(0,1 / 2)$ and let $W_{n}$ be a modified $W$-mapping generated by $T_{1}, T_{2}, \ldots, T_{k}$ and $\alpha_{1 n}, \alpha_{2 n}, \ldots, \alpha_{k n}$. Suppose $F=\bigcap_{i=1}^{k} F\left(T_{i}\right) \neq \emptyset, \sum_{n=1}^{\infty} \lambda_{n}<\infty$ and each $I-T_{i}, i=1,2, \ldots, k$, is demiclosed at 0 . If $E$ satisfies Opial's condition, then the sequence $\left\{x_{n}\right\}$ defined by (7) converges weakly to a common fixed point of the family $\left\{T_{i}: i=\right.$ $1,2, \ldots, k\}$.

Proof. From the proof of Lemma 11, we know that $\left\{x_{n}\right\}$ is a bounded sequence in $C$. Since $E$ is uniformly convex, it must be reflexive. Therefore, there exists a subsequence $\left\{x_{n_{j}}\right\}$ in $\left\{x_{n}\right\}$ converging weakly to $u \in C$. By Lemma $11, \lim _{j \rightarrow \infty} \| x_{n_{j}}-$ $T_{i} x_{n_{j}} \|=0$ and $I-T_{i}$ is demiclosed at 0 for $i=1,2, \ldots k$, so we obtain $T_{i} u=u$. That is, $u \in F$. Suppose that there exists another subsequence $\left\{x_{n_{k}}\right\}$ of $\left\{x_{n}\right\}$ converging weakly to $v \in$ $C$. As above, we can prove $v \in F$. By (27) we know that $\lim _{n \rightarrow \infty}\left\|x_{n}-u\right\|$ and $\lim _{n \rightarrow \infty}\left\|x_{n}-v\right\|$ exist. Assume $v \neq u$. Then by the Opial's condition, we have

$$
\begin{aligned}
\lim _{n \rightarrow \infty}\left\|x_{n}-u\right\| & =\lim _{n_{j} \rightarrow \infty}\left\|x_{n_{j}}-u\right\|<\lim _{n_{j} \rightarrow \infty}\left\|x_{n_{j}}-v\right\| \\
& =\lim _{n \rightarrow \infty}\left\|x_{n}-v\right\|=\lim _{n_{k} \rightarrow \infty}\left\|x_{n_{k}}-v\right\| \\
& <\lim _{n_{k} \rightarrow \infty}\left\|x_{n_{k}}-u\right\|=\lim _{n \rightarrow \infty}\left\|x_{n}-u\right\|,
\end{aligned}
$$

which is a contradiction. Hence $u=v$. This implies that $\left\{x_{n}\right\}$ converges weakly to a common fixed point of the family $\left\{T_{i}\right.$ : $i=1,2, \ldots, k\}$.

Remark 14. Lemma 11, Theorem 12, and Theorem 13 extend Lemma 3.1, Theorem 3.3, and Theorem 3.2 of Khan et al. [4], respectively.

\section{Conflict of Interests}

The author declares that there is no conflict of interests.

\section{References}

[1] N. Shahzad and H. Zegeye, "Strong convergence of an implicit iteration process for a finite family of generalized asymptotically quasi-nonexpansive maps," Applied Mathematics and Computation, vol. 189, no. 2, pp. 1058-1065, 2007.

[2] K. Nakajo, K. Shimoji, and W. Takahashi, "On strong convergence by the hybrid method for families of mappings in Hilbert spaces," Nonlinear Analysis. Theory, Methods \& Applications, vol. 71, no. 1-2, pp. 112-119, 2009. 
[3] W. Takahashi and K. Shimoji, "Convergence theorems for nonexpansive mappings and feasibility problems," Mathematical and Computer Modelling, vol. 32, no. 11-13, pp. 1463-1471, 2000.

[4] A. R. Khan, A.-A. Domlo, and H. Fukhar-ud-din, "Common fixed points Noor iteration for a finite family of asymptotically quasi-nonexpansive mappings in Banach spaces," Journal of Mathematical Analysis and Applications, vol. 341, no. 1, pp. 1-11, 2008.

[5] S. S. Chang, H. W. J. Lee, C. K. Chan, and J. K. Kim, "Approximating solutions of variational inequalities for asymptotically nonexpansive mappings," Applied Mathematics and Computation, vol. 212, no. 1, pp. 51-59, 2009.

[6] N. Shahzad and A. Udomene, "Approximating common fixed points of two asymptotically quasi-nonexpansive mappings in Banach spaces," Fixed Point Theory and Applications, vol. 2006, Article ID 18909, 10 pages, 2006.

[7] L. Qihou, "Iterative sequences for asymptotically quasi-nonexpansive mappings," Journal of Mathematical Analysis and Applications, vol. 259, no. 1, pp. 1-7, 2001.

[8] M. K. Ghosh and L. Debnath, "Convergence of Ishikawa iterates of quasi-nonexpansive mappings," Journal of Mathematical Analysis and Applications, vol. 207, no. 1, pp. 96-103, 1997.

[9] H. K. Xu, "Approximating fixed points of nonexpansive mappings by the Ishikawa iteration process," Journal of Mathematical Analysis and Applications, vol. 178, no. 2, pp. 301-308, 1993. 


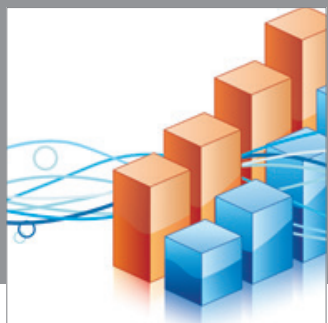

Advances in

Operations Research

mansans

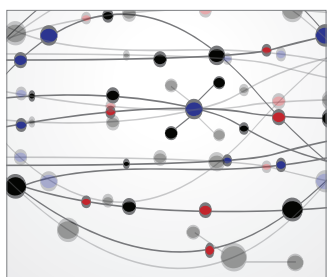

The Scientific World Journal
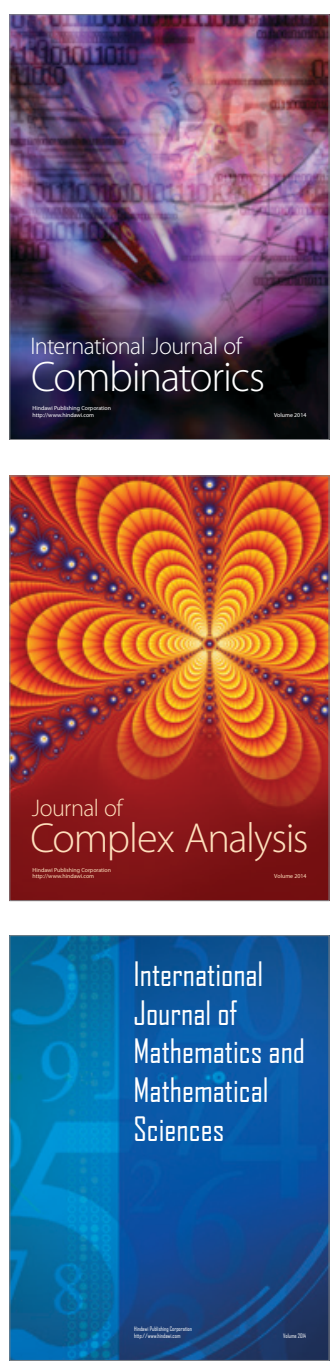
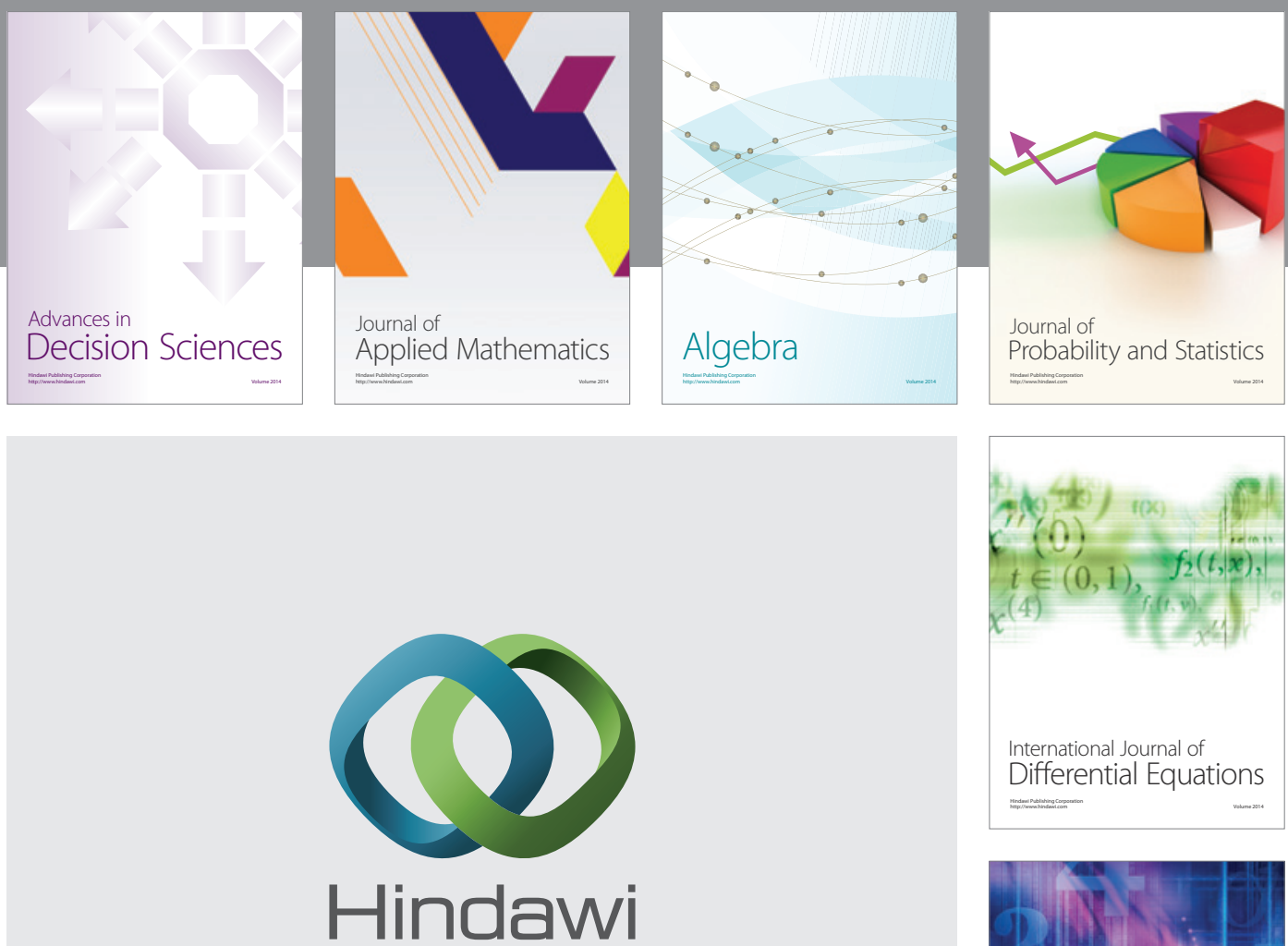

Submit your manuscripts at http://www.hindawi.com
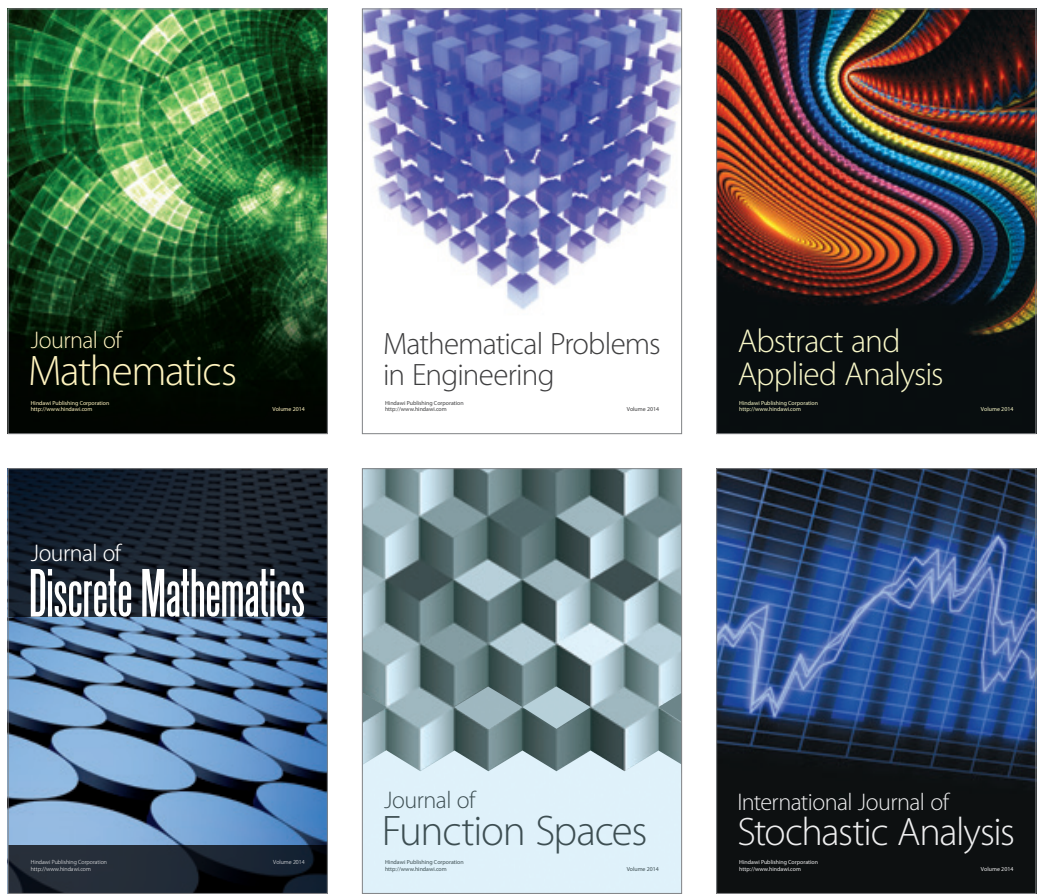

Journal of

Function Spaces

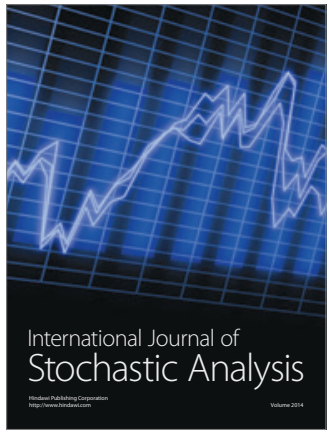

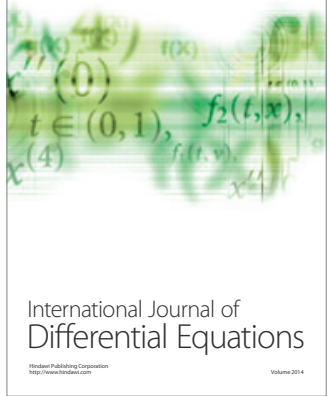
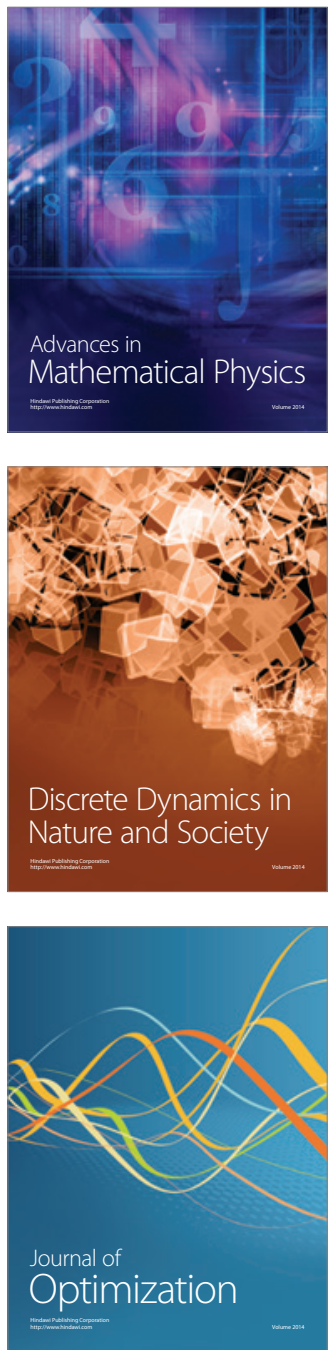